\title{
Unemployment, social capital, and subjective well-being
}

Winkelmann, Rainer

\begin{abstract}
It has been shown in past research that unemployment has a large negative impact on subjective well-being of individuals. In this paper, I explore whether and to what extent people with more social capital are sheltered from the harmful effects of unemployment. Using data from the German SocioEconomic Panel 1984-2004, I find that social capital is an important predictor of well-being levels, but there is no evidence that it moderates the effect of unemployment on well-being. Possible reasons for these findings are discussed, and suggestions for future research given.
\end{abstract}

DOI: https://doi.org/10.1007/s10902-008-9097-2

Posted at the Zurich Open Repository and Archive, University of Zurich

ZORA URL: https://doi.org/10.5167/uzh-2425

Journal Article

Published Version

Originally published at:

Winkelmann, Rainer (2009). Unemployment, social capital, and subjective well-being. Journal of Happiness Studies, 10(4):421-430.

DOI: https://doi.org/10.1007/s10902-008-9097-2 


\title{
Unemployment, Social Capital, and Subjective Well-Being
}

\section{Rainer Winkelmann}

\begin{abstract}
It has been shown in past research that unemployment has a large negative impact on subjective well-being of individuals. In this paper, I explore whether and to what extent people with more social capital are sheltered from the harmful effects of unemployment. Using data from the German Socio-Economic Panel 1984-2004, I find that social capital is an important predictor of well-being levels, but there is no evidence that it moderates the effect of unemployment on well-being. Possible reasons for these findings are discussed, and suggestions for future research given.
\end{abstract}

Keywords Happiness - Social activities · German Socio-Economic Panel · Regression analysis

\section{Introduction}

Past research has shown that individual unemployment has a large negative effect on mental health and subjective well-being (Wilson and Walker 1993; Clark and Oswald 1994). It is also typically found that the negative effect of unemployment on well-being goes well beyond the effect that the income loss associated with unemployment can bring about. Indeed, the non-pecuniary cost of unemployment seem to exceed the pecuniary cost (Winkelmann and Winkelmann 1998). It is less clear, however, what the ultimate origins of, and mechanisms behind, a diminished well-being of the unemployed are. A potentially

\footnotetext{
This paper was written while I was visiting scholar at the W.E. Upjohn Institute for Employment Research in Kalamazoo, MI. I am grateful to the Institute for its hospitality, to Andrew Clark, Andrew Oswald and three anonymous referees for valuable comments, and to the German Socio Economic Panel Study (GSOEP) at the German Institute for Economic Research (DIW), Berlin, for providing the data.
}

R. Winkelmann $(\bowtie)$

University of Zurich, Socioeconomic Institute, Zurichbergstr. 14, 8032 Zurich, Switzerland

e-mail: winkelmann@sts.uzh.ch 
useful line of further inquiry follows from the observation that the well-being loss is not at all uniform. Some people suffer much more than others. Understanding the sources of this heterogeneity will be helpful in suggesting explanations why there is a substantial negative effect on average.

The specific hypothesis of this paper is that the effect of unemployment on subjective well-being depends positively on the amount of social capital a person is equipped with, i.e., the higher the social capital, the smaller the decline in subjective well-being resulting from unemployment. There is prior evidence that social capital, defined as participation in social networks and social activities, is beneficial for the level of subjective well-being per-se (Helliwell and Putnam 2005; Grootet al. 2007).

The research question of this paper is different, namely whether changes in well-being due to unemployment are moderated by social capital. The basic idea is that employment is important for well-being because it increases an individual's perception of self-worth and self-esteem (Goldsmith et al. 1996a), whereas unemployment leads to a reduced locus of control and feelings of helplessness (Goldsmith et al. 1996b). Possibly, then, people with a larger social network and many alternative uses of their time might not be as much exposed as others to the adverse psychological mechanisms of unemployment, as the social network and these other activities can serve as substitutes for employment as a source of self-esteem and a controlled, structured life.

The research in this paper adds to other prior studies that have addressed different aspects of interest related to the heterogeneous responses of individuals to an unemployment experience. In one such strand, the focus has been on the importance of social norms. Clark (2003) reports that subjective well-being of the unemployed is higher, the higher the unemployment rate in the individual's reference group (at the regional, partner or household level, see also Shields and Wheatley Price 2005). Apparently, the more unemployment becomes the norm, the less individuals are affected by it. Lalive and Stutzer (2004) obtain the same result, albeit with a different identification strategy. Using Swiss data, they exploit the community variation in a referendum vote on an employment issue to define the social norm. The stronger the norm, the more quickly unemployed people find a new job, and the reduction in life-satisfaction is the larger, the stronger the norm is. As a further indicator on the salience of social norms, it is typically the case that the well-being loss caused by unemployment is larger for men than for women (Winkelmann and Winkelmann 1995).

Clark and Lelkes (2005) advance a "buffering hypothesis" according to which religion might provide insurance against some adverse life events, including unemployment, an hypothesis that finds support in their data. Smith et al. (2005) find evidence for a buffering effect of income. Finally, some studies have investigated the effect of adaptation. Individuals might learn how to live with unemployment over time, or downward adjust their expectations. Thus, the initial well-being loss should diminish over time, as a person's unemployment spell becomes longer. While this is a plausible hypothesis, and there is indeed ample evidence for hedonic adaptation with regard to income and other pecuniary aspects of life (Easterlin 2006), unemployment seems to be different, as the existing evidence points to non-existent or only very moderate adaptation to unemployment (Clark 2006; Winkelmann and Winkelmann 1998).

To test the hypothesis of social capital as a moderator variable, I make use of a relatively large sample of employment-unemployment transitions in the German SocioEconomic Panel. For people undergoing such a transition-being employed in one year, and being unemployed in the next round of the annual interviews-one can compute the individual change in subjective well-being associated with that transition. 
A unique feature of the employed data set is its sheer magnitude. There is information on 5,536 such transitions. This size distinguishes the present research from previous studies using a similar set-up. Winkelmann and Winkelmann (1998) and Clark (2003) — the latter for the British Household Panel Study-have only around 300 transitions at their disposition. The larger number in the current GSOEP is due to the long time span of the sample as 21 years of data were available for this analysis, as well as to the more recent booster samples, and it opens, at least in principle, the door to a much more detailed analysis. In addition, the GSOEP provides a relatively rich set of variables on social capital. The ones used here will relate both to daily time use and to activities that are undertaken regularly.

The general empirical strategy is as follows. For each person, we observe two measures of subjective well-being, one while being employed and another (roughly) one year later while being unemployed. Regression analysis is used to test the hypothesis that social capital moderates the effect that unemployment has on subjective well-being. To guard against potential omitted variable bias, these regressions also control for a number of common socio-economic background variables that have been identified by the past literature as important predictors of subjective well-being, plus time and region effects and all interactions thereof. One concern of the previous literature was the potential dependence of subjective well-being on personality factors. Such factors, if unaccounted for, can again lead to bias. In the present application, the object of interest is the change in well-being. Thus, personality effects are implicitly accounted for, as long as they are timeinvariant and as long as they affect well-being levels rather than the well-being/ unemployment gradient.

\section{Measurements and Sampling}

The empirical analysis is based on data from the German Socio-Economic Panel (GSOEP). The annual panel survey was initiated in 1984, first in West Germany with just under 6,000 households at the time. The sampling frame was extended to include about 2,000 East German households as early as June 1990. Since this round of interviews preceded the currency union on July 1 and the formal re-unification on Oct. 3 of that year, I drop these observations and include observations on East German households only from 1991 onwards. To counter the adverse effect of panel attrition on the sample sizes, supplementary booster samples were added in 1998 (about 1,100 households) and in 2000 (about 5,000 households). At current, the GSOEP interviews more than 20,000 individuals living in more than 10,000 households annually. The latest survey year available for this analysis was the year 2004.

The three key variables of the analysis are subjective well-being, the employment status, and social capital. As to the first, we follow the emotional model theory of subjective well-being, developed in the early 1980s by psychologist Ed Diener. According to this approach, the individuals' appraisals of their own lives (i.e., a person's individual judgment about his current status in the world) capture the essence of well-being (Diener 1984, Diener et al. 1985, 1999). The literature has identified three core components of subjective well-being: positive affect, (the lack of) negative affect, and general life satisfaction (i.e., subjective appreciation of life's rewards), separable constructs that can be independently examined. We focus here on the latter, general life satisfaction, elicited on a single item 11 point scale. The exact question of the survey reads as follows: "How satisfied are you with your life, all things considered? Please answer according to the following scale: "0" means completely dissatisfied, "10" means completely satisfied". 
The employment status distinguishes between gainful employment and unemployment, where unemployment is based on a registration criterion. This definition, while in some sense not ideal, is dictated by data considerations. Otherwise required questions on active search and availability were not included in the earlier years of the GSOEP (until and including 1993). Unemployment thus was at the time defined in terms of not working and being registered, and we follow this definition.

Third, an operational definition of social capital is needed. Social capital is inherently difficult to measure, as are indeed human and physical capital, and there is no universally accepted definition. According to Putnam (2000, p. 19), "social capital refers to connections among individuals - social networks and the norms of reciprocity and trustworthiness that arise from them." Social capital can be measured at the community and at the individual level. Attempts to operationalize social capital have focused on the incidence and intensity of political and social engagement (voting, volunteering in political or social organizations), informal social ties (such as entertaining friends at home), tolerance and trust.

The definition used in this analysis is dictated by the questions that are available in the German Socio-Economic Panel. While questions on tolerance and trust have been included only 2003, there have been questions on participation in social and political activities in earlier rounds of the survey. These questions were included repeatedly but not always.

I concentrate here on six distinct activities, and the question whether or not the person engages in any of these activities with at least a weekly frequency. The selected activities include attending cultural events, attending entertainment events, engaging in active sports, visiting friends, relatives or neighbors, engaging in voluntary work in political or social organizations, and attending church services. This information can be entered in two distinct ways. In a first approach, the social capital before starting unemployment is approximated by a set of 0/1 dummy variables in that year. Second, the long-run social capital of a person is approximated by taking the average activity indicators (one for each activity) over all available years for that person. This alternative measure is useful if feedback effects from unemployment to social capital are negligible, because averages can be formed for all persons in the sample, whereas individual year observations are missing for the years where the questions were not included. Using averages thus leads to larger sample sizes.

The reference sample in this paper consists of all individuals in the sample who made a transition from employment to unemployment between two consecutive survey years. Over the full stretch of the available panel years 1984-2004, there are 5,536 such transitions. Compared to earlier related papers on such work-to-unemployment transitions, where only a few hundred observations were available, this is a huge difference. As a consequence, one would hope that with such a sample, it becomes meaningful not only to calculate mean changes in subjective well-being, but in addition to explore the determinants of heterogeneity in these changes in detail. Note that since the sampling is conditional on being observed in employment in $t$ and on being observed in unemployment in $t+1$, there is a natural upper limit to the elapsed duration of the unemployment spell at the time of the second interview in $t+1$ (typically less than a year). Thus, the well-being effects of longterm unemployment cannot be studied within this sample.

\section{Empirical Results}

As an introduction to the data, Table 1 shows the means, and the estimated standard errors of the means, of the main variables used in this study, separately for men and for women. 
Table 1 Descriptive statistics

\begin{tabular}{lcc}
\hline & Men $(\mathrm{n}=3,059)$ & Women $(\mathrm{n}=2,477)$ \\
\hline SWB in $t$ (while employed) & $6.478(0.036)$ & $6.438(0.039)$ \\
SWB in $t+1$ (while unemployed) & $5.624(0.039)$ & $5.890(0.042)$ \\
German nationality & $0.767(0.008)$ & $0.828(0.008)$ \\
Age & $39.372(0.241)$ & $38.377(0.243)$ \\
Older than 45 & $0.391(0.009)$ & $0.343(0.010)$ \\
Married & $0.578(0.009)$ & $0.597(0.010)$ \\
Social capital & & \\
Attending cultural events & $0.010(0.002)$ & $0.004(0.002)$ \\
Attending entertainment events & $0.110(0.007)$ & $0.060(0.006)$ \\
Sport & $0.181(0.008)$ & $0.161(0.009)$ \\
Visiting friend, relatives & $0.394(0.013)$ & $0.356(0.014)$ \\
Engaging in voluntary work & $0.076(0.004)$ & $0.032(0.004)$ \\
Attending church services & $0.056(0.006)$ & $0.055(0.006)$ \\
\hline
\end{tabular}

* All social capital variables are measured in $t$. Dummy variables are coded as 1 if the activity is conducted "at least once a week"

Standard errors in parentheses

We obtain the well-known result that people are on average less well off when being unemployed rather than employed. For men, the average drop in well-being amounts to 0.85 (on the $0-10$ scale); for women it is 0.55 . The mean age is 39 for men, compared to a mean age of 38 for women. A total of 58 and 60 percent of men and women, respectively, are married. Foreigners are overrepresented relative to what one would expect from a random sample of the German resident population, but not necessarily so from the unemployment population. In terms of activities that in combination approximate social capital, it emanates that visiting friends and neighbors is the most frequently reported activity: 40 percent of all men, and 36 percent of all women, engage in this activity at least once per week. The next most frequently chosen activity is sports, whereas cultural events are cited least frequently by both men and women ( 1 percent and 0.4 percent only).

Figure 1 documents the amount of heterogeneity in well-being responses to unemployment. For four percent of men, and six percent of women, becoming unemployed is associated with a well-being loss of five or more, all on the $0-10$ well-being scale. For 43 percent of men, and 48 percent of women, the well-being loss runs between minus and minus four. The remaining persons report no change, or even an increase in subjective well-being.

Table 2 shows the estimation results for several regressions with well-being change as dependent variable, and socio-economic background factors as explanatory variables. The models also include a set of year dummies as well as a set of dummies for the state of residence ("Bundesland"). No controls for social capital are included yet. The method is ordinary least squares. The standard errors in parentheses account for potential heteroscedasticity and clustering at the individual level (since some persons are included with several transitions in the sample). The same model was estimated for three samples, a full sample, a male-only sample and a female-only sample, respectively.

In this table, a positive coefficient indicates a moderation of the effect: an increase in the associated variable leads to a smaller reduction in well-being when transiting from employment to unemployment. The table shows that unemployment "hurts less" for 


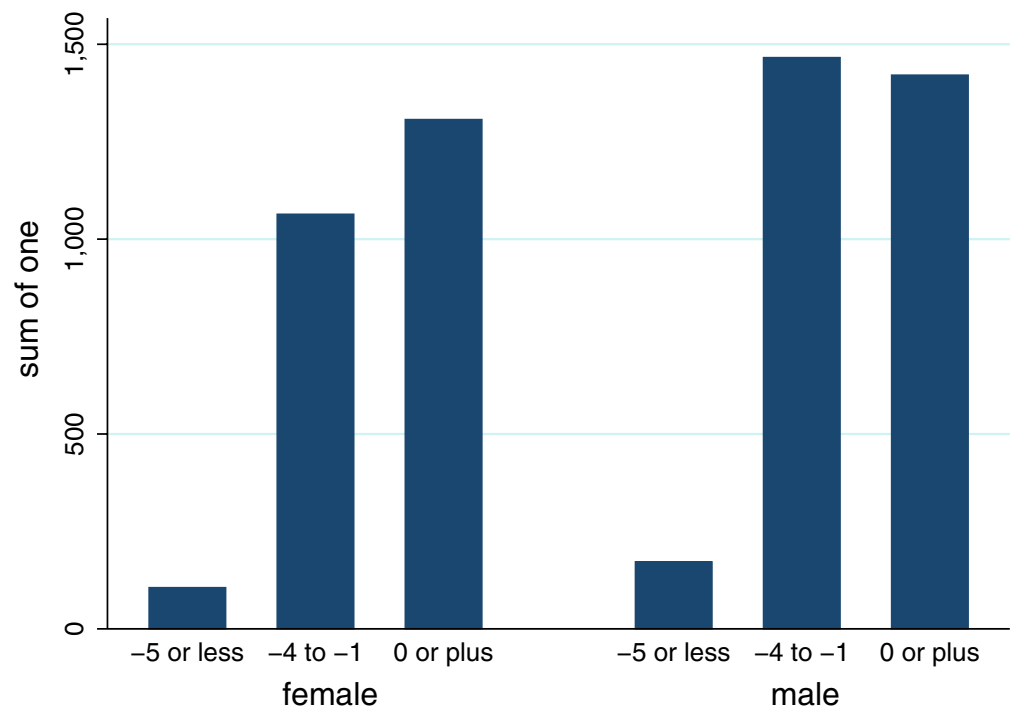

Fig. 1 Distribution of well-being loss of the unemployed, by sex

Table 2 Regression of SWB-loss on socio-economic characteristics

\begin{tabular}{llll}
\hline Dependent variable: $S W B_{t+1}-S W B_{t}$ & & & \\
\hline & All & Men & Women \\
\hline Male & $-0.275(0.060)$ & & \\
\# of previous spells & $0.098(0.048)$ & $0.084(0.066)$ & $0.158(0.076)$ \\
Duration $\leq$ 2 months & $-0.038(0.090)$ & $0.094(0.129)$ & $-0.101(0.131)$ \\
Duration not known & $-0.034(0.069)$ & $0.026(0.099)$ & $-0.065(0.099)$ \\
German nationality & $0.122(0.092)$ & $0.052(0.123)$ & $0.188(0.147)$ \\
Aged 25-34 & $0.184(0.107)$ & $0.441(0.150)$ & $0.019(0.157)$ \\
Aged 35-44 & $0.062(0.109)$ & $0.278(0.152)$ & $-0.001(0.164)$ \\
Aged 45 or older & $0.326(0.104)$ & $0.564(0.149)$ & $0.186(0.153)$ \\
Married & $0.028(0.074)$ & $-0.053(0.106)$ & $0.096(0.109)$ \\
University graduate & $0.146(0.138)$ & $0.031(0.193)$ & $0.224(0.211)$ \\
Region \& time effects & Yes & Yes & Yes \\
Number of observations & 5,536 & 3,059 & 2,477 \\
R-squared & 0.07 & 0.11 & 0.13 \\
Prob $>F$ & 0.00 & 0.01 & 0.00 \\
\hline
\end{tabular}

women than for men, for older people (aged 45 or older) relative to those under 25 , and for women who had already previous unemployment episodes. Thus, there is some evidence for an habituation effect but only for women.

The importance of social norms-if acting for example through the regional unemployment rates - is captured in the region and time effects. These are significant as a group. All the other effects are statistically insignificant. For instance, the duration of the current spell-whether or not it lasted for at most 2 months, does not make a difference. The 
Table 3 Are people with a more active social life happier?

\begin{tabular}{|c|c|c|c|c|}
\hline \multicolumn{5}{|l|}{ Dependent variable: $S W B$ in $t$} \\
\hline & \multicolumn{2}{|l|}{ Activities in $t$} & \multicolumn{2}{|c|}{ Average activities } \\
\hline & Male & Female & Male & Female \\
\hline Unemployment & $-1.158(0.034)$ & $-0.851(0.034)$ & $-1.303(0.021)$ & $-0.897(0.021)$ \\
\hline German nationality & $0.171(0.025)$ & $0.248(0.027)$ & $0.113(0.014)$ & $0.201(0.015)$ \\
\hline Married & $0.316(0.021)$ & $0.360(0.018)$ & $0.323(0.012)$ & $0.388(0.011)$ \\
\hline University graduate & $0.216(0.028)$ & $0.122(0.034)$ & $0.190(0.016)$ & $0.108(0.020)$ \\
\hline Attending cultural events & $0.183(0.069)$ & $0.384(0.069)$ & $0.356(0.074)$ & $0.574(0.073)$ \\
\hline Attending entertainment events & $0.014(0.031)$ & $0.059(0.039)$ & $-0.061(0.031)$ & $0.000(0.039)$ \\
\hline Sport & $0.281(0.021)$ & $0.273(0.021)$ & $0.438(0.016)$ & $0.513(0.017)$ \\
\hline Visiting friend, relatives & $0.168(0.019)$ & $0.279(0.018)$ & $0.245(0.015)$ & $0.392(0.015)$ \\
\hline Engaging in voluntary work & $0.122(0.030)$ & $0.195(0.039)$ & $0.146(0.022)$ & $0.186(0.032)$ \\
\hline Attending church services & $0.158(0.030)$ & $0.247(0.027)$ & $0.209(0.019)$ & $0.354(0.018)$ \\
\hline Region \& time effects & Yes & Yes & Yes & Yes \\
\hline Age dummies & Yes & Yes & Yes & Yes \\
\hline Observations & 41,991 & 44,940 & $1,33,270$ & $1,41,797$ \\
\hline R-squared & 0.089 & 0.083 & 0.090 & 0.082 \\
\hline
\end{tabular}

overall explanatory power of these models is quite low, as the R-squared statistics of at most 13 percent reveal. Most of the variation in the well-being change of unemployment remains unexplained.

\subsection{The Effect of Social Capital on Well-Being}

Helliwell and Putnam conclude their analysis by stating that "social capital is strongly linked to subjective well-being through many independent channels and in several different forms." (2005, p. 455). Theirs is a statement about the level of subjective well-being. To reproduce their findings in the context of the GSOEP data, Table 3 reports estimates from an augmented subjective well-being regression model, where social capital variables are included in addition to the standard socio-economic variables. The models are estimated separately for men and women, and in two specifications, a first one with the period specific activity variables (measured in $t$ ) and a second with the individual average of these activity variables over all available years. As mentioned in the previous section, the sample sizes increase substantially when averages are used, due to the way the data were collected.

Note that this is now a level model, and not a model for only those transiting from employment to unemployment. This approach leads to a completely different sample with a much larger number of observations. The evidence from these models supports the prior claims on the importance of social capital. With the exception of the attendance of entertainment events, all activities have a positive and statistically significant effect on subjective well-being. Quantitatively the largest effect comes from sport and, for women, the attendance of cultural events. As most effects are in the 0.2-0.6 range, these are substantial and large effects. They can be compared to the average drop in well-being due to unemployment, say a one point decrease on the on the $0-10$ well-being scale. In other words, a single social capital component can increase well-being by as much as half of the employment-unemployment gap. 
Table 4 Are people with a more active social life better prepared for unemployment?

\begin{tabular}{|c|c|c|c|c|}
\hline \multicolumn{5}{|l|}{ Dependent variable: $\triangle S W B$} \\
\hline & \multicolumn{2}{|l|}{ Activities in $t$} & \multicolumn{2}{|c|}{ Average activities } \\
\hline & Male & Female & Male & Female \\
\hline \multicolumn{5}{|l|}{ Activities } \\
\hline Attending cultural events & $0.112(0.511)$ & $-0.994(0.187)$ & $0.221(0.710)$ & $0.264(0.752)$ \\
\hline Attending entertainment events & $-0.097(0.247)$ & $0.061(0.300)$ & $-0.352(0.266)$ & $0.135(0.384)$ \\
\hline Sport & $-0.072(0.207)$ & $-0.136(0.207)$ & $0.023(0.142)$ & $0.011(0.171)$ \\
\hline Visiting friend, relatives & $0.193(0.145)$ & $-0.017(0.164)$ & $0.188(0.134)$ & $0.092(0.144)$ \\
\hline Engaging in voluntary work & $0.129(0.263)$ & $-0.095(0.512)$ & $0.079(0.206)$ & $0.088(0.403)$ \\
\hline Attending church services & $0.131(0.280)$ & $0.578(0.316)$ & $0.329(0.189)$ & $0.302(0.226)$ \\
\hline Region \& time effects & Yes & Yes & Yes & Yes \\
\hline Socio-economic controls ${ }^{\mathrm{a}}$ & Yes & Yes & Yes & Yes \\
\hline Observations & 1,066 & 881 & 2,919 & 2,382 \\
\hline R-squared & 0.04 & 0.06 & 0.03 & 0.03 \\
\hline Prob $>F^{\mathrm{b}}$ & 0.842 & 0.575 & 0.259 & 0.801 \\
\hline
\end{tabular}

${ }^{a}$ Socio-economic controls include all variables used in Table 2

b The $p$-value is for an $F$-test of joint significance of the social capital variables

In general, the social capital effects are larger when the average rather than the period specific social capital measures are used. A possible explanation is that the period measures are subject to larger measurement error, and that the resulting attenuation bias is reduced when averages are used. Of course, we have to add the caveat that these effects are not necessarily causal, as they may also capture, fully or in part, personality differences, meaning that otherwise more satisfied people are also more likely to attend cultural events, engage actively in sports, etc. While such level models cannot address this identification problem, a model based on differences avoids some of it, as personality factors are now accounted for.

Thus, Table 4 shows regression results for models where well-being loss is the dependent variable. The regressions differ in two aspects from those in Table 2. First, while they include the same variables as the models estimated in Table 2, they add the social capital variables as further regressors. Second, because information on social capital is missing for some years and some individuals, the sample sizes are reduced.

Recall the central question of the paper, namely whether more social capital shields people from the harmful impact of unemployment on well-being. In other words, do people with a larger social capital experience a smaller well-being loss when becoming unemployed than others, ceteris paribus, after controlling for other determinants. The answer to this question seems to be "no". Regardless of whether men or women are considered, and whether activities in $t$ or average activities are used, practically all the effects are individually insignificant. If anything, there is some evidence that attending church services regularly has a moderating impact on the well-being loss. More importantly, though, one cannot reject the null-hypotheses of no explanatory power of the six social capital variables as a group, using standard $F$-tests, in all four cases. In other words, the individual level variation in subjective well-being responses appears to be unrelated to social capital. 


\section{Discussion}

In this paper, I have analyzed data from the German Socio-Economic Panel 1994-2004, extracting a sample of individuals who transited from employment to unemployment between two interviews. The data confirmed the standard result that there is a large reduction in subjective well-being during unemployment. The paper then proceeded to investigate the determinants of variation in well-being loss due to unemployment between people, in particular the hypothesis that more social capital reduces the harmful effect of unemployment on well-being.

This hypothesis could not be confirmed by the data. While social capital was found to have a significant positive effect on well-being levels, there was no effect on well-being differentials generated by unemployment. This is a rather unexpected result. A-priori, one would expect that since variation in well-being levels across individuals is substantially and robustly related to socio-economic characteristics and social capital, then part of this association should be also count for variation in well-being changes across individuals. Three potential explanations for the absence of such a finding come to mind. First, as mentioned before, these social capital variables might proxy for (time invariant) personality differences, which would explain why the effects disappear when modeling changes over time. Second, not finding an effect does not prove that their is none. Some of the point estimates are quite sizeable but the sampling error is very large. Essentially, it appears that the employed measure of subjective well-being is very noisy, and further progress could possibly depend on more precise measures of subjective well-being. Third, measurement error is also likely to affect the employed measure of social capital. For instance, it would be desirable in future work to obtain more precise measures of the intensity with which a given activity is pursued, beyond the simple "less than once a week"/"at least once a week distinction".

Obviously, more work needs to be done on the question of how unemployment, social capital and well-being interact. Neither the presence nor the absence of a causal effect of a social capital channel regarding the size of the well-being loss due to unemployment could be definitely established. We are still a long way from answering the question "Why are the unemployed so unhappy " (Winkelmann and Winkelmann 1998). Still, the results and patterns presented in this paper seem sufficiently strong and intriguing to justify further research in this area, using improved methods and the continuously expanding data base provided by the GSOEP.

\section{References}

Clark, A. (2003). Unemployment as a social norm: psychological evidence from panel data. Journal of Labor Economics, 21, 323-350.

Clark, A. (2006). A note on unhappiness and unemployment duration. Applied Economics Quarterly, 52, 291-308.

Clark, A., \& Lelkes, O. (2005). Deliver us from evil: Religion as insurance. PSE Working Paper No. 2005/43.

Clark, A. E., \& Oswald, A. (1994). Unhappiness and unemployment. Economic Journal, 104, 648-659.

Diener, E. (1984). Subjective well-being. Psychological Bulletin, 95, 542-575.

Diener, E., Emmons, R. A., Larsen, R. J.,\& Griffin, S. (1985). The satisfaction with life scale. Journal of Personality Assessment, 49(1), 71-75.

Diener, E., Suh, E. M., Lucas, R. E., \& Smith, H. L. (1999). Subjective well-being: Three decades of progress. Psychological Bulletin, 125, 276-302.

Easterlin, R. (2006). Building a better theory of well-being. In L. Bruni, P. L. Porta (Eds.), Economics \& happiness: Framing the analysis (pp. 29-64). New York: Oxford University Press. 
Goldsmith, A. H., Veum, J. R., \& Darity, W. (1996a). The impact of labor force history on self-esteem and its component parts, anxiety, alienation and depression. Journal of Economic Psychology, 17, 183-220.

Goldsmith, A. H., Veum, J. R., \& Darity, W. (1996b). The psychological impact of unemployment on joblessness. Journal of Socio-Economics, 25, 333-358.

Groot, W., van den Brink, H. M., \& van Praag, B. (2007). The compensating income variation of social capital. CESifo Working Paper No. 1889.

Helliwell, J. F., \& Putnam R. D. (2005). The social context of well-being. Chapter 17. In F. Huppert, N. Beylis, B. Keverne (Eds.), The science of well-being, Oxford University Press.

Lalive, R., \& Stutzer, A. (2004). The role of social work norms in job searching and subjective well-being. Journal of the European Economic Association, 2, 696-719.

Putnam, R. D. (2000). Bowling alone: The collapse and revival of American community. New York: Simon\& Schuster.

Smith, D. M., Langa, K. M., Kabeto, M. U., \& Ubel, P. A. (2005). Health, wealth and happiness: financial resources buffer subjective well-being after the onset of a disability. Psychological Science, 16, 663-666.

Shields, M. A., \& Wheatley Price, S. (2005). Exploring the economic and social determinants of psychological well-being and perceived social support in England. Journal of the Royal Statistical Society A, $168,513-537$.

Wilson, S. H., \& Walker, G. M. (1993). Unemployment and health: A review. Public Health, 107, $153-162$.

Winkelmann, L., \& Winkelmann, R. (1995). Happiness and unemployment: A panel data analysis for Germany. Konjunkturpolitik, 41(4), 293-307.

Winkelmann, L., \& Winkelmann, R. (1998). Why are the unemployed so unhappy? Evidence from panel data. Economica, 65, 1-15. 